\title{
Mechanochemical solid state synthesis of a bifunctional copper(I)/N- heterocyclic carbene complex and its catalytic activity in hydrogenative transformations
}

\author{
Ina Remy-Speckmann ${ }^{a,+}$ \\ Birte M. Zimmermann ${ }^{\mathrm{a},+}$ \\ Mahadeb Gorai ${ }^{a, b}$ \\ Martin Lerch ${ }^{\mathrm{a}}$ \\ Johannes F. Teichert*a,b \\ a Technische Universität Berlin \\ Institut für Chemie \\ Straße des 17. Juni 115 \\ 10623 Berlin \\ Germany \\ ${ }^{\mathrm{b}}$ Technische Universität Chemnitz \\ Fakultät für Naturwissenschaften \\ Straße der Nationen 62 \\ 09111 Chemnitz \\ + These authors contributed equally to this work. \\ johannes.teichert@chemie.tu-chemnitz.de
}

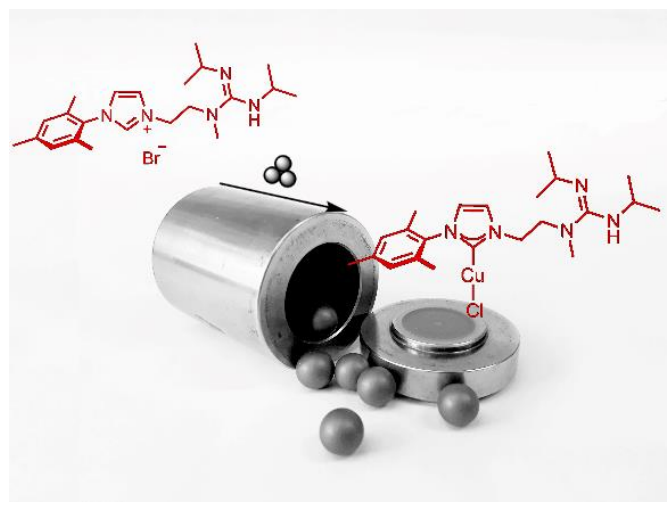

\begin{abstract}
A sophisticated bifunctional catalyst bearing a copper(I)/N-heterocyclic carbene and a guanidine organocatalyst has been prepared by a mechanochemical synthesis in a ball mill. This approach circumvents commonly employed silver(I) complexes which are associated with significant and undesired waste formation. Due to the bifunctional nature of the desired complex, earlier mechanochemical conditions were not applicable and a new protocol based on cheap and readily available K3PO4 as base has been developed. The resulting complex has been shown to be active in a variety of reduction/hydrogenation transformations employing dihydrogen as terminal reducing agent.
\end{abstract}

Key words mechanochemical synthesis, planetary ball mill, copper, N-heterocyclic carbenes, bifunctional catalysis, hydrogen activation

Some prominent goals of green chemistry heralded for synthetic chemistry are minimization or even complete prevention of chemical waste, the use of innocuous chemicals and replacement of hazardous reagents, atom efficient reactions and overall safer chemical processes. ${ }^{1,2}$ Therefore, one current challenge for synthesis is the development of green and environmentally friendly routes to access value-added products. One important way to more economical syntheses is the concept of catalysis to avoid stoichiometric amounts of reactants and to design reactions more atom efficient. ${ }^{1-3}$ As one case in point, copper $(\mathrm{I}) / \mathrm{N}$-heterocyclic carbene $(\mathrm{NHC})$ complexes are broadly applicable for a wide variety of catalytic transformations. ${ }^{4-6}$

While generally there are many different synthetic routes to transition metal/NHC complexes ${ }^{7,8-10}$ not all of them are applicable to the preparation of copper(I)/NHC compounds (Scheme 1).5,6,8,1114 Generally, the so-called "direct route" via the appropriate imidazol(in)ium salt, a copper precursor and a suitably strong base $(\mathrm{NaH}, \mathrm{NaOtBu}, \mathrm{KHMDS} \text { or } n \mathrm{BuLi})^{15}$ is challenging for copper complexes such as $\mathbf{3}$ as it tends to give low yields (Scheme 1, a). ${ }^{5,6,8,11-14}$ An elegant protocol employing $\mathrm{K}_{2} \mathrm{CO}_{3}$ as weak base in combination with copper(I) salts for simple copper(I)/NHC complexes has been disclosed (Scheme $1, b) .{ }^{16}$ While this variant is the method of choice due its simplicity and practicability, other alternatives have to be sought in cases where this direct synthesis approaches fail: On the one hand, the so-called "built-in base" route relies on the use of $\mathrm{Cu}_{2} \mathrm{O}$ which can be directly reacted with a suitable precursor $\mathbf{1}$ (Scheme $1, \mathrm{c}) .{ }^{17}$ On the other hand, the most common approach hinges upon the use of the preliminary preparation of a silver(I)/NHC complex (2) followed by facile transmetallation to copper(I) (Scheme 1, d). In some cases, this transmetallation step is carried out in situ. $9,10,18$ Notably, these generally successful synthetic routes produce a considerable amount of transition metal waste and are therefore in misalignment with the principles of green chemistry.

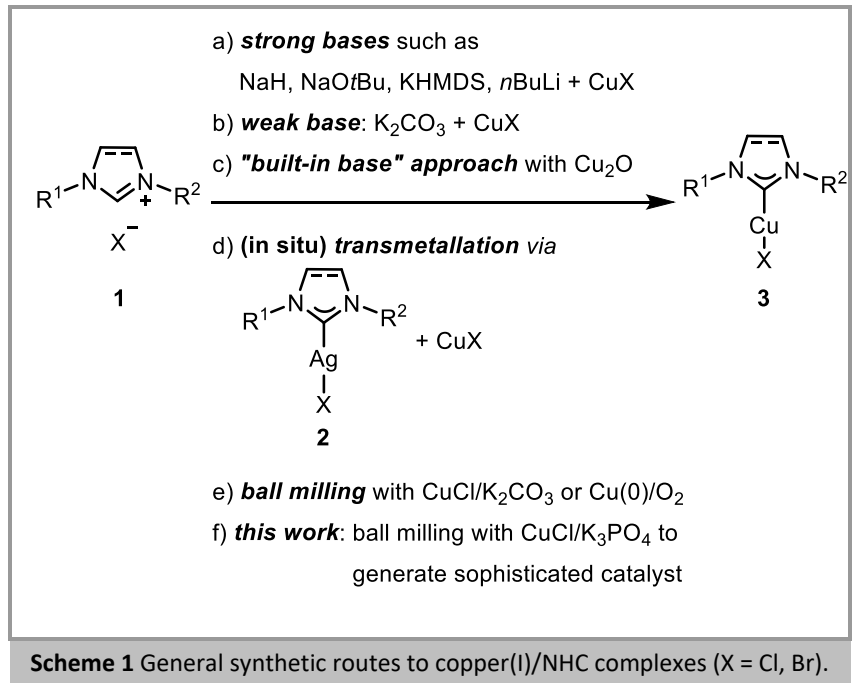




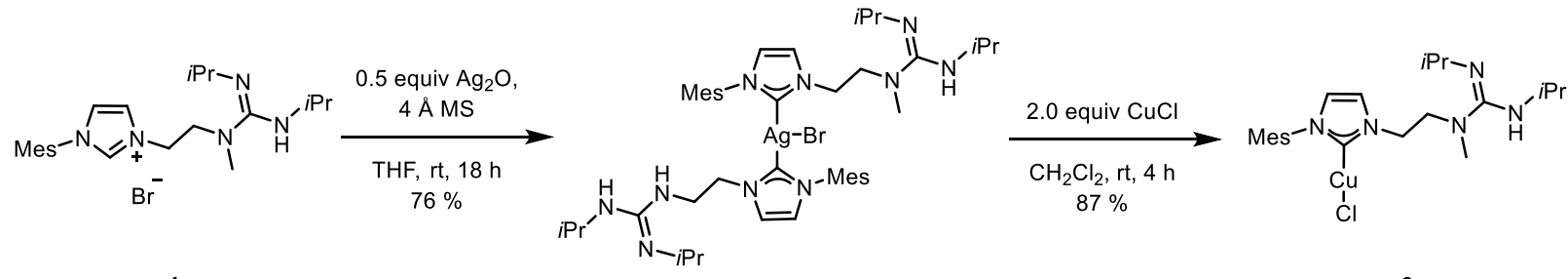

Scheme 2 Published liquid state synthesis of $\mathbf{6}$ via silver complex $\mathbf{5}$ (Mes = Mesityl). ${ }^{19,20}$

Synthesis via mechanochemical methods offers elegant and atomeconomic alternatives to liquid state synthesis approaches. ${ }^{21,22}$ Very recently, the possibility of synthesizing copper(I)/NHC complexes in the ball mill has been disclosed (Scheme 1, e). ${ }^{23-25}$ These approaches are promising due to the avoidance of unwanted transition metal waste and/or organic solvents. Two possible mechanochemical pathways have been presented for the synthesis of copper(I)/NHC complexes: First, the complexes can be synthesized by milling the ligand precursor 1 with metallic copper powder in air. ${ }^{23}$ Another mechanochemical pathway was published using $\mathrm{K}_{2} \mathrm{CO}_{3}$ as a base and copper(I) chloride. ${ }^{24,25}$ This procedure is practical, avoids the use of solvents, and relies on an abundant and cheap base.

We have recently disclosed an unprecedented ester reduction with $\mathrm{H}_{2}$ as terminal reducing agent utilizing bifunctional copper(I)/NHC complex 6 bearing a guanidine moiety as additional catalytic unit. ${ }^{20}$ This catalysts acts by employing the copper(I)/NHC complex for $\mathrm{H}_{2}$ activation on the one hand and by using the guanidine subunit for organocatalytic simultaneous activation of the ester on the other hand. Following a previously established synthetic pathway, ${ }^{19}$ we have found that transmetallation via silver(I)/NHC complex $\mathbf{5}$ was the only viable entry point to this sophisticated bifunctional catalyst (Scheme 2). ${ }^{26}$ First, the silver(I)/NHC complex 5 had to be synthesized and isolated prior to transmetallation with copper(I) chloride. ${ }^{19,20}$ The required formation of silver(I) complex $\mathbf{5}$ diminishes the overall yield of copper complex $\mathbf{6}$. As an additional disadvantage, the silver(I) byproducts have to be carefully removed in order to maintain reproducible results in the copper(I) catalysis. ${ }^{20}$ We deemed this synthetic route unattractive with regards to sustainable synthesis due to the silver waste generated in the process and sought to replace the transmetallation route with a more atom economic approach to circumvent these problems.

We therefore examined different approaches to avoid the transmetallation step and to establish a protocol for direct synthesis of $\mathbf{6}$ in solution (Table 1, liquid state approaches). The use of strong bases such as $\mathrm{NaOtBu}$ or $n \mathrm{BuLi}$ or the weak base $\mathrm{Et}_{3} \mathrm{~N}$ in an attempted direct approach did not lead to the desired product (Table 1, a and c). Furthermore, utilizing $\mathrm{CuCl}$ and $\mathrm{K}_{2} \mathrm{CO}_{3}$ as a base or $\mathrm{Cu}_{2} \mathrm{O}$ for a "built-in base" approach lead to the formation of a catalytically inactive $\mathrm{CO}_{2}$ adduct of the desired complex 6 (Table 1 , $\mathrm{b}$ and c). ${ }^{27,28}$ We hypothesize that in the $\mathrm{CO}_{2}$ adduct, the guanidine moiety is unavailable to perform its assisting part in catalysis through hydrogen-bonding interaction. ${ }^{20}$

Since our attempts to establish direct synthetic routes to 6 in liquid state were not fruitful, we turned our attention to mechanochemical synthesis of bifunctional catalyst 6 , based on two recent reports of preparation of copper(I)/NHC complexes in a ball mill. ${ }^{23-25}$ However, with each of the two approaches, additional challenges associated with the bifunctional nature of complex 6 arose. On the one hand, the use of copper powder and oxygen ${ }^{23}$ as starting materials for the mechanochemical approach seemed not feasible for the synthesis of complex $\mathbf{6}$ due to its high propensity to oxidation. On the other hand, the second published mechanochemical synthesis protocol employing copper(I) chloride and $\mathrm{K}_{2} \mathrm{CO}_{3}{ }^{24,25}$ seemed not applicable due to the facile formation of $\mathrm{CO}_{2}$ adducts as observed in the liquid state synthesis with $\mathrm{K}_{2} \mathrm{CO}_{3}$. Nevertheless, using copper(I) chloride as the copper source seemed promising, therefore the mechanochemical synthesis of 6 was attempted using $\mathrm{CuCl}$ and various bases (Table 1, solid state approaches).

Table 1 Liquid and solid state approaches to synthesize complex 6.

\begin{tabular}{|c|c|c|}
\hline $\mathrm{Mes}^{-\mathrm{N}_{+}^{-}}$ & 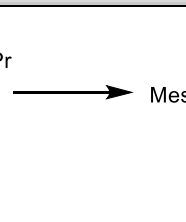 & $\overbrace{}^{\mathrm{PPr}-\mathrm{N}}$ \\
\hline 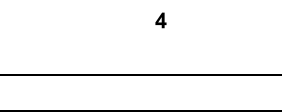 & Reagents & Results \\
\hline \multicolumn{3}{|l|}{ Liquid state approaches } \\
\hline a) Strong bases & $\begin{array}{l}\mathrm{CuCl} \text { and } n \mathrm{BuLi} \text { or } \\
\mathrm{NaOtBu}\end{array}$ & $\begin{array}{l}\text { No product formation } \\
\text { observed }\end{array}$ \\
\hline b) "Built-in base" approach & $\mathrm{Cu}_{2} \mathrm{O}$ & $\begin{array}{l}\text { Catalytically inactive } \\
\mathrm{CO}_{2} \text { adduct }\end{array}$ \\
\hline \multirow[t]{2}{*}{ c) Weak bases } & $\mathrm{CuCl}$ and $\mathrm{NEt}_{3}$ & $\begin{array}{l}\text { No product formation } \\
\text { observed }\end{array}$ \\
\hline & $\mathrm{CuCl}$ and $\mathrm{K}_{2} \mathrm{CO}_{3}$ & $\begin{array}{l}\text { Catalytically inactive } \\
\mathrm{CO}_{2} \text { adduct }\end{array}$ \\
\hline \multicolumn{3}{|l|}{ Solid state approaches } \\
\hline \multirow[t]{2}{*}{ d) Strong bases } & $\begin{array}{l}\mathrm{CuCl} \text { and } \mathrm{NaOtBu} \\
\text { or } \mathrm{NaOH} \text { or } \\
\text { KHMDS }\end{array}$ & $\begin{array}{l}\text { No product formation } \\
\text { observed }\end{array}$ \\
\hline & $\mathrm{CuCl}$ and $\mathrm{NaH}$ & $\begin{array}{l}\text { Unselective product } \\
\text { formation observed, } \\
\text { purification not } \\
\text { feasible }\end{array}$ \\
\hline e) "Built-in base" approach & $\mathrm{Cu}_{2} \mathrm{O}$ & $\begin{array}{l}\text { No product formation } \\
\text { observed }\end{array}$ \\
\hline f) Weak base & $\mathrm{CuCl}$ and $\mathrm{K}_{3} \mathrm{PO}_{4}$ & $\begin{array}{l}\text { Successful product } \\
\text { formation }\end{array}$ \\
\hline
\end{tabular}

The mechanochemical synthesis was carried out in a planetary ball mill. ${ }^{29}$ Copper(I) chloride, imidazolium salt $\mathbf{4}$ and the appropriate base were mixed in a molar ratio of $1: 1: 1.5$ and grinded for 4 hours. Employing strong bases such as KHMDS, NaOtBu or $\mathrm{NaOH}$ did not lead to the desired product. All three approaches have in common that the conjugated acid is a liquid. In the literature, the improvement of mechanochemical 


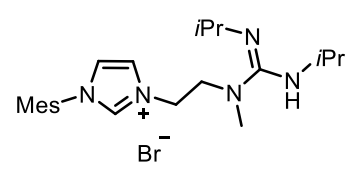

4

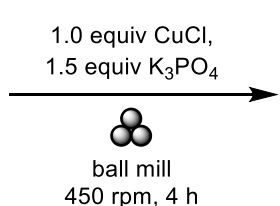

$450 \mathrm{rpm}, 4 \mathrm{~h}$

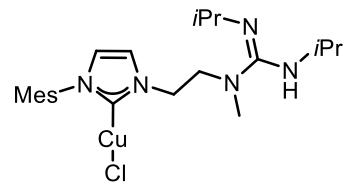

Equation 1 Mechanochemical synthesis of complex 6

syntheses by addition of small amounts of a liquid have been reported (LAG, liquid-assisted grinding).22 However, in our case, the formation of small amounts of liquid during the milling process lead to agglutination of the remaining powder and therefore insufficient homogenization of the reaction mixture. This led to a mixture of compounds, in which the envisaged complex 6 could not be identified (Table 1, d).

A different approach was made using sodium hydride as a base. Instead of small amounts of liquid, here, deprotonation leads to the formation of dihydrogen. Hence, another mill was utilized for this approach. ${ }^{30}$ Unfortunately, a successful synthesis of 6 directly from 4 was not possible under these conditions. NMR analysis of the resulting mixture indicated the presence of 6 , but also of unwanted side-products that could not be identified. Purification of 6 from this complex mixture turned out not to be feasible (Table 1, d). Further modifications of the milling conditions did not lead to the elimination of these side-products, therefore the experiments with $\mathrm{NaH}$ as a base were discontinued.

The direct transition of the "built-in base" approach conditions to mechanochemical synthesis (copper(I) oxide and imidazolium salt 4 as starting materials), lead to no product formation (Table 1, e).

Based on these results, we devised new mechanochemical conditions for the preparation of bifunctional copper(I)/NHC complex 6 relying on a weak base approach. Successful formation of copper(I) complex 6 was achieved by using readily available $\mathrm{K}_{3} \mathrm{PO}_{4}$ as a base in combination with $\mathrm{CuCl}$ (Equation 1; Table 1, f). ${ }^{31}$ The starting materials were mixed in a steel vessel and grinded at $450 \mathrm{rpm}$ for a total of four hours. After ball milling, an off-white powder was obtained which gave complex 6 in very good yield of $91 \%$ after the usual workup and no further purification step. NMR analysis of 6 matched previously reported data ${ }^{19,20}$ and showed no side products. It has to be mentioned that complex 6 synthesized via the mechanochemical route is isolated as a $\mathrm{CH}_{2} \mathrm{Cl}_{2}$ adduct $\left(6 / \mathrm{CH}_{2} \mathrm{Cl}_{2}=1: 1\right)$ as confirmed by NMR spectroscopy and elemental analysis. $^{32}$

Comparing catalyst 6 from mechanochemical synthesis $(\mathbf{6 b m})$ with its counterpart from the liquid state transmetallation route (6ls), we found that $\mathbf{6 b m}$ was catalytically active, however displaying slightly diminished activity (Scheme 3). This was shown in lower overall conversion of ethyl benzoate (7) to benzyl alcohol (8) and lower yield ( $65 \%$ conv. and $53 \%$ yield with $6 \mathbf{b m}$, in comparison to $100 \%$ conv. and $80 \%$ yield with 6ls; Scheme 3, a). We hypothesize that the higher amount of $\mathrm{CH}_{2} \mathrm{Cl}_{2}$, which is not a suitable solvent for catalytic ester reduction with $\mathrm{H}_{2},{ }^{20}$ led to lower catalyst activity. ${ }^{33}$ The copper(I)-catalyzed 1,2-reduction of functionalized ester 9 was also successfully achieved using the ball mill synthesized bifunctional catalyst $6 \mathbf{b m}$, again with slightly diminished yields and conversions (Scheme 3, b).

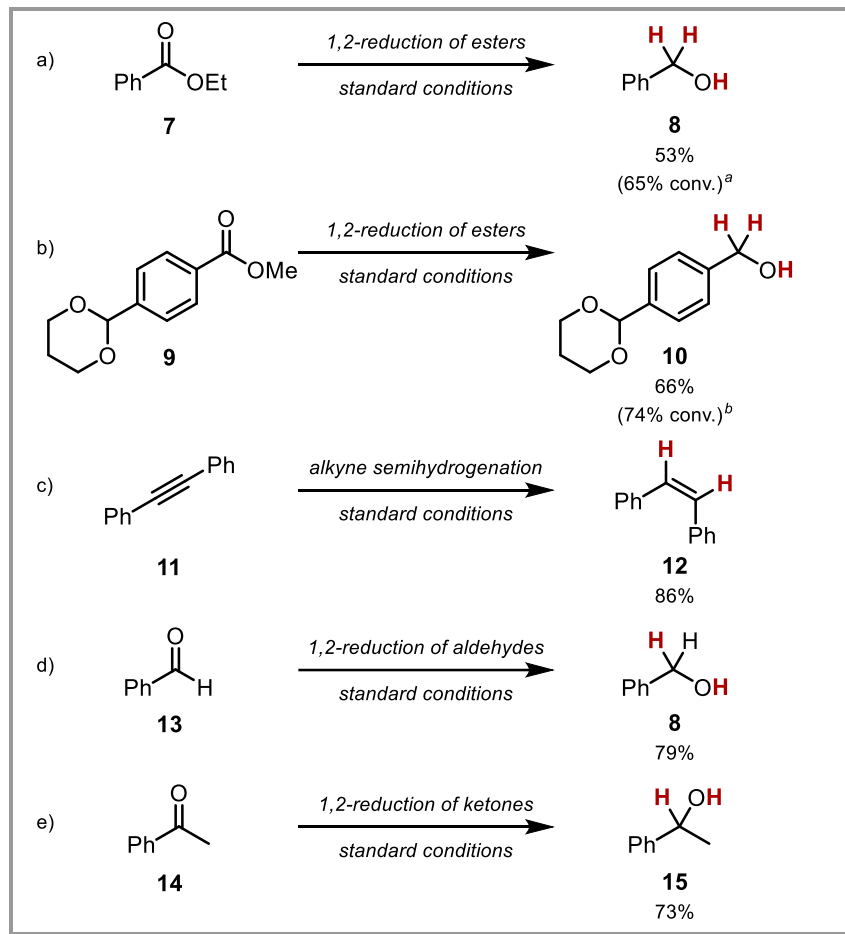

Scheme 3 Scope of ball mill-synthesized bifunctional catalyst $\mathbf{6 b m}$. Isolated yields under standard conditions: Substrate $(0.40 \mathrm{mmol}), 10 \mathrm{~mol} \%[\mathrm{Cu}] 6 \mathrm{bm}$, 1.1 equiv $\mathrm{NaOtBu}, 1.3$ equiv 15 -crown-5, 100 bar $\mathrm{H}_{2}$, 1,4-dioxane $(3 \mathrm{~mL})$, $70{ }^{\circ} \mathrm{C}, 24 \mathrm{~h}$. ${ }^{a}$ With liquid state synthesis complex 6ls: full conversion and $80 \%$ yield. ${ }^{b}$ With liquid state synthesis complex 6 ls: full conversion and $74 \%$ yield.

We were further interested in the demonstration of the applicability of the mechanochemically synthesized bifunctional complex $\mathbf{6}$. Application of the ball mill-synthesized complex 6bm in an alkyne semihydrogenation of tolane (11) gave (Z)-stilbene (12) with full stereoselectivity in good yield ( $86 \%$, Scheme $3, \mathrm{c}$ ). Therefore, 6bm behaves similarly to other copper(I)/NHC complexes in this transformation. ${ }^{34}$ The catalytic 1,2-reduction of carbonyl compounds is mainstay for copper(I)/NHC complexes, ${ }^{35}$ which is why we also tested $6 \mathbf{b m}$ in these transformations: The 1,2-reduction of benzaldehyde (13) and acetophenone (14) proceeded with good yields (Scheme 3, d and e). No aldol addition for the acetophenone substrate has been observed although working under strongly basic conditions. ${ }^{36}$

In conclusion, we have disclosed a practical approach to a sophisticated bifunctional copper(I)/NHC complex based on a mechanochemical protocol. This operationally simple synthetic route circumvents the previously necessary use of surplus transition metal reagents and therefore diminishes unwanted waste formation. The new protocol presented here is based on $\mathrm{K}_{3} \mathrm{PO}_{4}$ and has successfully displayed the activity of the resulting catalyst in a variety of hydrogenative transformations. Our results do not only add to the wide area of applications of mechanochemical synthesis 
but also showcase that transition metal complexes bearing additional functional groups can be prepared with a ball milling synthesis. We think that our protocol could be useful for the atom economic preparation of other complex catalysts, which are difficult or wasteful to be prepared by typical liquid state synthesis methods.

\section{Funding Information}

This research was funded by the Deutsche Forschungsgemeinschaft (DFG, German Research Foundation) under Germany's Excellence Strategy EXC 2008-390540038-UniSysCat, and through an Emmy Noether Fellowship for J.F.T. (TE1101/2-1). M.G. is supported by a fellowship by the Einstein Center for Catalysis $\left(E C^{2}\right)$.

\section{Acknowledgment}

Prof. Dr. Martin Oestreich (TU Berlin) is kindly thanked for generous support.

\section{Conflict of Interest}

The authors declare no conflict of interest.

\section{References and Notes}

(1) Sheldon, R. A., Chem. Soc. Rev. 2012, 41, 1437-1451.

(2) Anastas, P.; Eghbali, N., Chem. Soc. Rev. 2010, 39, 301-312.

(3) Barry M. Trost, Angew. Chem. Int. Ed. 1995, 34, 259-281.

(4) N. O. Thiel, F. Pape, J. F. Teichert in Homogeneous Hydrogenation with Non-Precious Catalysts; J. F. Teichert (Ed.); Wiley: Weinheim, 2019, 87-109.

(5) Lazreg, F.; Nahra, F.; Cazin, C. S., Coord. Chem. Rev. 2015, 293-294, 4879.

(6) Egbert, J. D.; Cazin, C. S. J.; Nolan, S. P., Catal. Sci. Technol. 2013, 3, 912.

(7) (a) Scattolin, T.; Nolan, S. P., Trends Chem. 2020, 2, 721-736. (b) Peris, E., Chem. Rev. 2018, 118, 9988-10031. (c) Hameury, S.; Frémont, P. de; Braunstein, P., Chem. Soc. Rev. 2017, 46, 632-733. (d) Hopkinson, M. N.; Richter, C.; Schedler, M.; Glorius, F., Nature 2014, 510, 485496. (e) Brown, J. M.; Dixneuf, P. H.; Fürstner, A.; Hegedus, L. S.; Hofmann, P.; Knochel, P.; van Koten, G.; Murai, S.; Reetz, M.; Glorius, F., N-Heterocyclic Carbenes in Transition Metal Catalysis, Vol. 21, Springer Berlin Heidelberg: Berlin, Heidelberg, 2007. (f) DíezGonzález, S.; Nolan, S. P., Coord. Chem. Rev. 2007, 251, 874-883.

(8) Danopoulos, A. A.; Simler, T.; Braunstein, P., Chem. Rev. 2019, 119, 3730-3961.

(9) Pape, F.; Teichert, J. F., Eur. J. Org. Chem. 2017, 29, 4206-4229.

(10) Nolan, S. P., N-Heterocyclic Carbenes in Synthesis, Wiley: Weinheim, 2006.

(11) Budagumpi, S.; Keri, R. S.; Achar, G.; Brinda, K. N., Adv. Synth. Catal. 2020, 362, 970-997.

(12) Lin, J. C. Y.; Huang, R. T. W.; Lee, C. S.; Bhattacharyya, A.; Hwang, W. S.; Lin, I. J. B., Chem. Rev. 2009, 109, 3561-3598.

(13) Nahra, F.; Gómez-Herrera, A.; Cazin, C. S. J., Dalton Trans. 2017, 46, $628-631$.

(14) Yong, X.; Thurston, R.; Ho, C.-Y., Synthesis 2019, 51, 2058-2080.

(15) For selected examples, see: (a) Arduengo, A. J.; Harlow, R. L.; Kline, M., J. Am. Chem. Soc. 1991, 113, 361-363. (b) Arduengo, A. J.; Dias, H. V. R.; Calabrese, J. C.; Davidson, F., Organometallics 1993, 12, 34053409. (c) Raubenheimer, H. G.; Cronje, S.; Olivier, P. J., J. Chem. Soc., Dalton Trans. 1995, 313. (d) Hu, X.; Castro-Rodriguez, I.; Olsen, K.; Meyer, K., Organometallics 2004, 23, 755-764. (e) Díez-González, S.; Kaur, H.; Zinn, F. K.; Stevens, E. D.; Nolan, S. P., J. Org. Chem. 2005, 70, 4784-4796. (f) Michon, C.; Ellern, A.; Angelici, R. J., Inorg. Chim. Acta 2006, 359, 4549-4556. (g) Díez-González, S.; Escudero-Adán, E. C.; Benet-Buchholz, J.; Stevens, E. D.; Slawin, A. M. Z.; Nolan, S. P., Dalton Trans. 2010, 39, 7595-7606.
(16) Santoro, O.; Collado, A.; Slawin, A. M. Z.; Nolan, S. P.; Cazin, C. S. J., Chem. Commun. 2013, 49, 10483-10485.

(17) Citadelle, C. A.; Le Nouy, E.; Bisaro, F.; Slawin, A. M. Z.; Cazin, C. S. J., Dalton Trans 2010, 39, 4489-4491.

(18) (a) van Veldhuizen, J. J.; Campbell, J. E.; Giudici, R. E.; Hoveyda, A. H. J. Am. Chem. Soc. 2005, 127, 6877-6882. (b) Brown, M. K.; May, T. L.; Baxter, C. A.; Hoveyda, A. H., Angew. Chem. Int. Ed. 2007, 46, 10971100. (c) Lee, Y.; Akiyama, K.; Gillingham, D. G.; Brown, M. K.; Hoveyda, A. H., J. Am. Chem. Soc. 2008, 130, 446-447. (d) May, T. L.; Brown, M. K.; Hoveyda, A. H., Angew. Chem. Int. Ed. 2008, 47, 73587362.

(19) Tai, C.-C.; Yu, M.-S.; Chen, Y.-L.; Chuang, W.-H.; Lin, T.-H.; Yap, G. P. A.; Ong, T.-G., Chem. Commun. 2014, 50, 4344-4346.

(20) Zimmermann, B. M.; Tran Ngoc, T.; Tzaras, D.-I.; Kaicharla, T.; Teichert, J.F., J. Am. Chem. Soc. 2021, DOI: 10.1021/jacs.1c09626.

(21) For reviews on mechanochemistry in general and selected examples of synthesis of transition metal complexes via mechanochemical approaches, see: (a) Beillard, A.; Quintin, F.; Gatignol, J.; Retailleau, P.; Renaud, J.-L.; Gaillard, S.; Métro, T.-X.; Lamaty, F.; Bantreil, X., Dalton Trans. 2020, 49, 12592-12598. (b) Beillard, A.; Bantreil, X.; Métro, T.X.; Martinez, J.; Lamaty, F., Chem. Rev. 2019, 119, 7529-7609. (c) Zaky, R.; Fekri, A., Appl. Organometal. Chem. 2019, e4786. (d) Andersen, J.; Mack, J., Green Chem. 2018, 20, 1435-1443. (e) Howard, J. L.; Cao, Q.; Browne, D. L., Chem. Sci. 2018, 9, 3080-3094. (f) Tan, D.; Friščić, T., Eur. J. Org. Chem. 2018, 18-33. (g) Hernández, J. G.; Bolm, C., J. Org. Chem. 2017, 82, 4007-4019. (h) Rightmire, N. R.; Hanusa, T. P., Dalton Trans. 2016, 45, 2352-2362. (i) Beillard, A.; Bantreil, X.; Métro, T.-X.; Martinez, J.; Lamaty, F., Dalton Trans. 2016, 45, 17859-17866. (j) Rightmire, N. R.; Hanusa, T. P., Dalton Trans. 2016, 45, 2352-2362. (k) Beillard, A.; Golliard, E.; Gillet, V.; Bantreil, X.; Métro, T.-X.; Martinez, J.; Lamaty, F., Chem. Eur. J. 2015, 21, 17614-17617.

(22) Friščić, T.; Mottillo, C.; Titi, H. M., Angew. Chem. Int. Ed. 2020, 59, 1018-1029.

(23) Beillard, A.; Métro, T.-X.; Bantreil, X.; Martinez, J.; Lamaty, F., Chem. Sci. 2017, 8, 1086-1089.

(24) Pisanò, G.; Cazin, C. S. J., Green Chem. 2020, 22, 5253-5256.

(25) Pisanò, G.; Cazin, C. S. J., ACS Sustain. Chem. Eng. 2021, 9, 9625-9631.

(26) For reviews on other multifunctional NHC ligands and transition metal complexes thereof, see: ref. (7d), (7f), (9) and Poyatos, M.; Mata, J. A.; Peris, E., Chem. Rev. 2009, 109, 3677-3707.

(27) The $\mathrm{CO}_{2}$ adduct has been identified via HRMS, see Supporting Information for details.

(28) For the synthesis and characterization of other guanidine $/ \mathrm{CO}_{2}$ adducts see: (a) Selig, P. (Ed.) Topics in Heterocyclic Chemistry, Vol. 51, Springer: Cham, 2017. (b) Selig, P., Ed. Topics in Heterocyclic Chemistry, Vol. 50, Springer: Cham, 2017.

(29) Experiments were carried out with a Fritsch Pulverisette 7 classic line in a $12 \mathrm{~mL}$ steel beaker with six steel balls ( $1 \mathrm{~cm}$ in diameter). See the Supporting Information for more details.

(30) To prevent damage due to the development of pressure inside the milling vessel, gastight $45 \mathrm{~mL}$ zirconia beakers equipped with six zirconia balls $(1.5 \mathrm{~cm}$ in diameter) and the Fritsch Pulverisette 7 premium line were used.

(31) Mechanochemical synthesis procedure for 6: The product was synthesized using a Fritsch Pulverisette 7 classic line, a high-energy planetary ball mill. The starting materials 1-(2-(2,3-diisopropyl-1methylguanidino)ethyl)-3-mesityl- $1 \mathrm{H}$-imidazol-3-ium bromide (4, $75 \mathrm{mg}, 0.16 \mathrm{mmol}, 1.0$ equiv), $\mathrm{CuCl}$ ( $17 \mathrm{mg}, 0.16 \mathrm{mmol}, 1.0$ equiv) and $\mathrm{K}_{3} \mathrm{PO}_{4}$ (53 mg, $0.25 \mathrm{mmol}, 1.5$ equiv) were filled into a $12 \mathrm{~mL}$ steel vessel equipped with six steel balls ( $1 \mathrm{~cm}$ diameter). The beaker was sealed in an Ar-filled glovebox. Milling was carried out with $450 \mathrm{rpm}$ for a total of four hours. After each hour the milling was paused for 30 minutes to avoid overheating of the machine. The raw product was obtained as an off-white powder after milling. The ground product was mixed with $\mathrm{CH}_{2} \mathrm{Cl}_{2}(3 \mathrm{~mL})$ and the resulting suspension was filtered over a PTFE syringe filter $(0.45 \mu \mathrm{m})$. The filtrate was concentrated under reduced pressure. The product 6 was obtained as the $\mathrm{CH}_{2} \mathrm{Cl}_{2}$ adduct as a colourless solid ( $86 \mathrm{mg}, 0.15 \mathrm{mmol}, 91 \%$ ). 
(32) If complex 6 is formed via the liquid state synthesis, see ref. (19) and (20), also a $\mathrm{CH}_{2} \mathrm{Cl}_{2}$ adduct is isolated, however with a $6 / \mathrm{CH}_{2} \mathrm{Cl}_{2}$ ratio of 2:1.

(33) Analysis by ${ }^{31} \mathrm{P}-\mathrm{NMR}$ spectroscopy did not show any data for a possible coordination of residual phosphate to the guanidine moiety.

(34) (a) Semba, K.; Kameyama, R.; Nakao, Y., Synlett 2015, 26, 318-322. (b) Pape, F.; Thiel, N. O.; Teichert, J. F., Chem. Eur. J. 2015, 21, 1593415938. (c) Thiel, N. O.; Teichert, J. F., Org. Biomol. Chem. 2016, 14 10660-10666. (d) Wakamatsu, T.; Nagao, K.; Ohmiya, H.; Sawamura, M., Organometallics 2016, 35, 1354-1357. (e) Pape, F.; Teichert, J., Synthesis 2017, 49, 2470-2482. (f) Thiel, N. O.; Kemper, S.; Teichert, J. F., Tetrahedron 2017, 73, 5023-5028. (g) Thiel, N. O.; Pape, F.; Teichert, J. F. in Homogeneous Hydrogenation with Non-Precious Catalysts Teichert, J. F., Ed., Wiley, 2019, 87-109. (h) Brechmann, L. T.; Teichert, J. F., Synthesis 2020, 52, 2483-2496.

(35) (a) Mahoney, W. S.; Stryker, J. M., J. Am. Chem. Soc. 1989, 111, 88188823. (b) Chen, J.-X.; Daeuble, J. F.; Brestensky, D. M.; Stryker, J. M., Tetrahedron 2000, 56, 2153-2166. (c) Chen, J.-X.; Daeuble, J. F.; Stryker, J. M., Tetrahedron 2000, 56, 2789-2798. (d) Shimizu, H. Igarashi, D.; Kuriyama, W.; Yusa, Y.; Sayo, N.; Saito, T., Org. Lett. 2007, 9, 1655-1657. (e) Shimizu, H.; Nagasaki, I.; Matsumura, K.; Sayo, N.; Saito, T., Acc. Chem. Res. 2007, 40, 1385-1393. (f) Junge, K.; Wendt, B.; Addis, D.; Zhou, S.; Das, S.; Fleischer, S.; Beller, M., Chem. Eur. J. 2011, 17, 101-105. (g) Trose, M.; Lazreg, F.; Chang, T.; Nahra, F.; Cordes, D. B.; Slawin, A. M. Z.; Cazin, C. S. J., ACS Catal. 2017, 7, 238242.

(36) (a) Mahrwald, R., Modern Aldol Reactions, Wiley: Weinheim, 2004. (b) Aggarwal, V. K., Arai, N., Bergin, E., Buitrago Sanatnilla, A., Carreira, E. M. Science of Synthesis: Stereoselective Synthesis Vol. 2, Thieme: Stuttgart, 2011 
